\title{
Experimental Study on Incentive Effect of Cost and Schedule Factors Based on Earned Value Method
}

\author{
Huanbin Liu, a , Lingyun $\mathrm{Li}^{2, \mathrm{~b}}$ \\ ${ }^{1,2}$ School of Economics and Management, Xidian University, Xi'an 710071, China \\ an21498879@qq.com, ${ }^{b} 136658485 @ q q . c o m$
}

Keywords: Earned value method, schedule and cost, incentive effect

\begin{abstract}
The contract between the contractor and the customer means that the project contract has the same binding effect on both parties. Earned value method is the main method of project schedule and cost control. It can accurately control the process of the project, but how to ensure the quality of the project is not clear. This paper will use experimental research methods to explore the impact of two incentive contracts that based on cost and schedule, and then explore the impact of incentives on the contractor effort. The result is helpful for the customer to control the quality effectively in the project implementation.
\end{abstract}

\section{Introduction}

One of the methods to effectively control the project is the earned value method. Jinhui Zhou[1] uses the earned value method that involves three variables which obtains cost, planned value and absolute differences between them, to control the software project. Ziman Cheng [2] considers the influence of risk factors on the comprehensive evaluation accuracy of engineering cost schedule, and uses the trapezoidal fuzzy mathematics theory combined with the quality earned value method to establish the risk-quality earned value evaluation index system. Yanming Wei[3] constructed a cost deviation analysis framework for land development and consolidation based on the work breakdown structure. In terms of the defects and improvement research of earned value management methods, Rodney [4] and Fleming [5] have found that the traditional project earned value management method does not distinguish between activities on critical paths and non-critical paths. Using this method is easy to lead mis-evaluation of schedule performance. Anbari [6] expended the difference in progress and cost in the earned value management method, extended the calculation method for predicting the completion cost, and increased the estimate of the project completion time. Chunsheng Cui[7] incorporates quality management factors into traditional earned value management. Anbang Qi[8] proposed the existence of a violation of the statistical principle in the relative differences in project costs and absolute differences. Rui Li[9] introduced the two variables of unemployed earned value and risk earned value into the earned value distribution problem, and improved the cost performance evaluation method. The cost estimation model proposed by Qiang Mou[10] improved the ability of traditional earned value method to predict the completion cost estimate. Guangping Liu[11,12] improved the traditional earned value method, and made the total construction period and total cost more accurate, and the performance appraisal was 
more accurate.

In view of the fact that most of the current earned value research focuses on controlling project schedules and costs, many studies focus on program improvement, but lack the analysis and research of cost and schedule factors. This paper will use the experimental method to explore the incentive effect of cost and schedule, and then explore the relationship between the progress cost and profit of both parties. Research can help to improve the scientific management of the project and help to coordinate the interests of both parties.

\section{Research Methods}

\subsection{Experimental principle}

In this paper, the experimental method is used to study the incentive effect of the different incentive contracts between the customer and the contractor, which based on the earned value method. The customer uses the earned value method to control the project. The deviation of the project management includes the progress deviation and the cost deviation. The deviation is determined by the difference between the earned value and the actual value. Earned value and cost are influenced by the contractor's efforts. The higher efforts result in great earned value and low cost. The contractor's cost increases as the its effort increases, and the marginal cost also rising when effort increase.

It is assumed that the contractor's effort cost is $\mathrm{c}\left(\mathrm{c}=0.5^{*} e^{\wedge} 2\right)$. The advancement of the schedule allows the customer to obtain income greater than the progress deviation compares to the early completion of the project, and the delay of the schedule will cause the customer to suffer losses greater than the progress deviation due to the project's failure to put into use. Therefore, the deviation of the progress brought to the customer is magnified. The output gain from the schedule deviation is cSV-bSV. This paper assumes that the value of amplification factor c is 1.1.

The contractor's income is the sum of the contract amount A and the project owner's incentives minus the effort cost, that sum is the income function. The income of the project owner mainly comes from the project quality, project cost and project output to the customer. In summary, the income function of the contractor and the owner is (1)and (2).

$$
\begin{aligned}
& \text { contractor: } \mathrm{A}+b(S V+C V)+0.5 e^{2} \\
& \text { customer: } e+(1-b) S V+(1.1-\mathrm{b}) C V
\end{aligned}
$$

(A, base amount; $b$, Incentive coefficient; $e$, effort; $S V$, Schedule deviation; $C V$, Cost deviation)

After the customer and the contractor reach a willingness to cooperate, the two parties sign the contract. Customer can provide two types of incentive contract control projects, the contract are progress-based incentive contracts and cost-based incentive contracts. The incentive amount of the contracts is different, specifically refers to the size of the incentive coefficient $b$; the contractor makes the corresponding effort level $e$ according to the incentive coefficient $b$.

Project process diagram:

\begin{tabular}{cccc}
$\mathrm{t}=0$ & $\mathrm{t}=1$ & $\mathrm{t}=2$ & $\mathrm{t}=3$ \\
\hline Signing & customer: $\mathrm{b}$ & contractor: $\mathrm{e}$ & gain profit
\end{tabular}

$\mathrm{t}=0$ : A contract is signed between the project owner and the contractor;

$\mathrm{t}=1$ : The project owner makes an incentive decision (b) according to the deviation;

$\mathrm{t}=2$ :The contractor makes an effort decision(e) according to excitation coefficient(b);

$\mathrm{t}=3$ : Both owner and contractor get profit. 


\subsection{Experimental design}

The goal of this study is based on the incentive effects under different stimulus contracts. The stimulating effect can be described by the contractor's effort level e and their respective benefits. This experiment uses an independent sample method, the purpose of which is to eliminate the influence of the learning effects formed by other experimental groups on the behavior of participants. Since the participants are relatively homogenous, it is assumed that the participants are small and the impact is small and negligible.

The deviation is diffident because it is related to the observation point, the project itself, the planned cost and the actual cost. In order to simplify the experiment operation, the following special values of cost and progress deviation are taken to replace the possible deviation combination. Among them, the progress deviation are ahead, no deviation, and delay; the cost deviation are over-spending, no deviation, and saving. The specific values refer to the following table1. In terms of progress, positive values represent advance, negative values represent delays, and 0 represents no deviation. In terms of cost deviation; positive values represent savings, negative values represent overruns, and 0 represents no deviations. The specific values refer to the following table 1 . The combination of $S V$ and $C V$ is random, with a total of $5 * 5$ deviation combinations.

Table 1 Deviation random values

\begin{tabular}{|l|l|l|l|l|l|}
\hline$S V$ & -3 & -1 & 0 & 1 & 3 \\
\hline$C V$ & -3 & -1 & 0 & 1 & 3 \\
\hline
\end{tabular}

In this paper, two experimental groups are designed, which are progress-type incentive contracts and cost-type incentive contracts. The average number of participants was assigned to 25 trial periods, and each experiment period was randomly assigned to the above contract. Each trial period was carried out from contract signing to completion, and 2 participants respectively as the project owner and contractor role during each trial period. During the test, the roles of the two players did not change. In the experiment, the deviation combinations were randomly selected and decided separately.

The incentive plan based on schedule and cost will affect the decision of both parties in the contract, because both of them will make the most favorable decision for their own interests. The experiment aims to explore the utility of progress and cost in earned value management, as well as stability. Here are the following assumptions:

Hypothesis 1: Progress-based incentive contracts are more stimulating to contractors.

Hypothesis 2: Cost-based incentive contracts are more stimulating to contractors.

The process of from signing contract to the completion has the following steps:

1) Participants sign an incentive contract under a certain incentive mode as a reward scheme based on random grouping.

2) The Customer makes an incentive coefficient $(b, 0 \sim 1)$ according to SV and CV.

3 ) The contractor makes decision (e) according to incentive coefficient (b,1 10).

4) Both customer and contractors get their own income according to the contract.

\section{Conclusion}

\subsection{Statistical Analysis}

The experimental data of incentive coefficient and effort under different incentive contracts are obtained. A total of 50 records based on progress contract and cost contract were summarized. Based on the schedule and cost, the incentive coefficient of the owner under the contract is $b 1$ and 
$b 2$, and the corresponding contractor's efforts are $e 1$ and $e 2$. The results of the above experimental data analysis are shown in Table 2.

Table 2 Statistical analysis

\begin{tabular}{|l|l|l|l|l|}
\hline & $b 1$ & $e ~ 1$ & $b 2$ & $e$ 2 \\
\hline average & 0.3844 & 3.2200 & 0.4376 & 5.1800 \\
\hline variance & 0.2525 & 1.5410 & 0.1949 & 1.1313 \\
\hline
\end{tabular}

It can be seen from Table 2 that the mean value of the incentive coefficient of the incentive-based contract based on the schedule is less than the mean value of the incentive coefficient based on the cost incentive contract $(b 1<b 2)$, and the fluctuation of the contract-based incentive coefficient based on cost is small. Contractors based on cost contracts are more engaged. This shows that rich incentives can lead to higher contractor efforts. In comparison, the incentives of the owners under the cost-based incentive contract are large, and the contractor's efforts are also high. Based on the above analysis, the cost-based incentive contract is suitable for short-term engineering projects, because the stimulus is quick; the progress-based incentive contract is applicable to long-term projects, because the stimulus effect is stable.

\subsection{Variance analysis}

In order to clarify whether there is a significant difference between the incentive effect of the incentive contract and the contractor which based on the situations of progress and cost, the experimental data is further analyzed by variance. The results are shown in Table 3.

Table 3 Variance Analysis Table for b and e

\begin{tabular}{|l|l|l|l|l|l|}
\hline Dependent Variable: e & Pr>F \\
\hline Source & DF & $\begin{array}{l}\text { Sum } \\
\text { Squares }\end{array}$ & $\begin{array}{l}\text { Mean } \\
\text { Square }\end{array}$ & F Value & 0.0005 \\
\hline Model & 1 & 48.02 & 48.02 & 13.88 & \\
\hline Error & 48 & 166.02 & 3.4588 & & \\
\hline $\begin{array}{l}\text { Corrected } \\
\text { Total }\end{array}$ & 49 & 49 & 214.04 & & Pr>F \\
\hline Dependent Variable: b & DF & $\begin{array}{l}\text { Sum } \\
\text { Squares }\end{array}$ & $\begin{array}{l}\text { Mean } \\
\text { Square }\end{array}$ & F Value & 0.4084 \\
\hline Source & 1 & 0.0354 & 0.0354 & 0.7 & \\
\hline Model & 48 & 2.4413 & 0.0509 & & \\
\hline Error & 49 & 2.4767 & & & \\
\hline $\begin{array}{l}\text { Corrected } \\
\text { Total }\end{array}$ & & & & & \\
\hline
\end{tabular}

According to the results of Table 3, the analysis of variance of effort e shows that the probability $(p=0.0005<0.05)$ indicates that the contractor's efforts under different contractual contracts are significantly different. Similarly, the analysis of variance of the incentive coefficient b shows that the probability ( $p=0.4084>0.05$ ) indicates that there is no significant difference in the incentive level of the owners under different contractual situations. It can be seen that the same incentive coefficient has different incentive effects on the contractors when they sign different incentive contracts. 


\subsection{Profit Analysis}

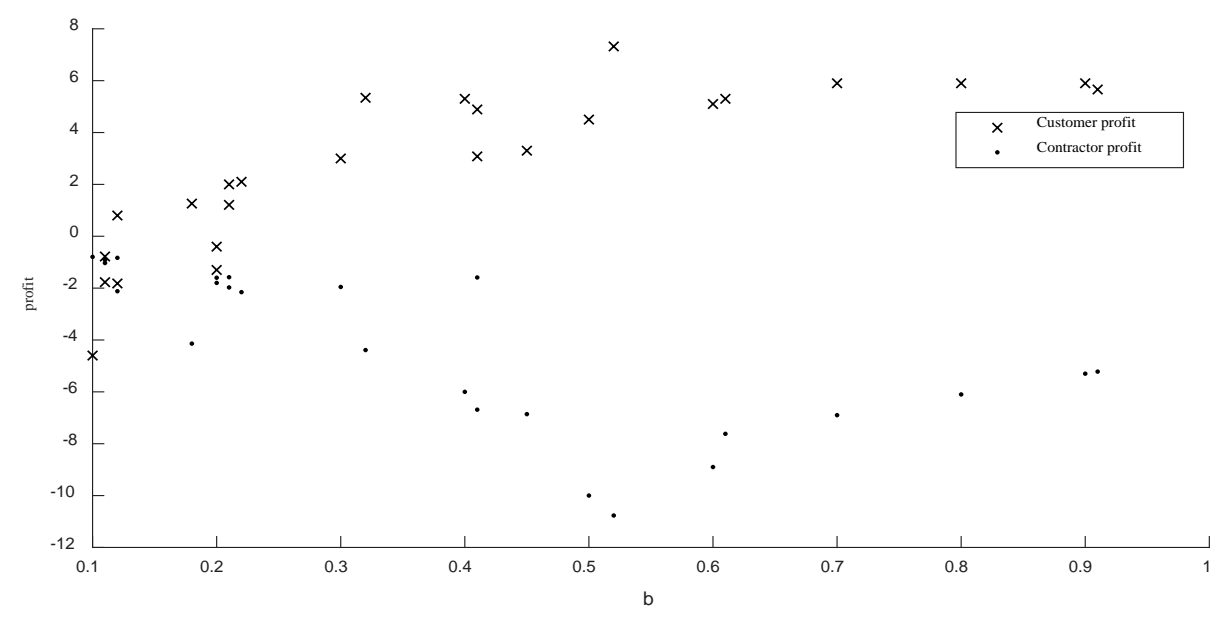

Fig.1 Progress-based incentive contract

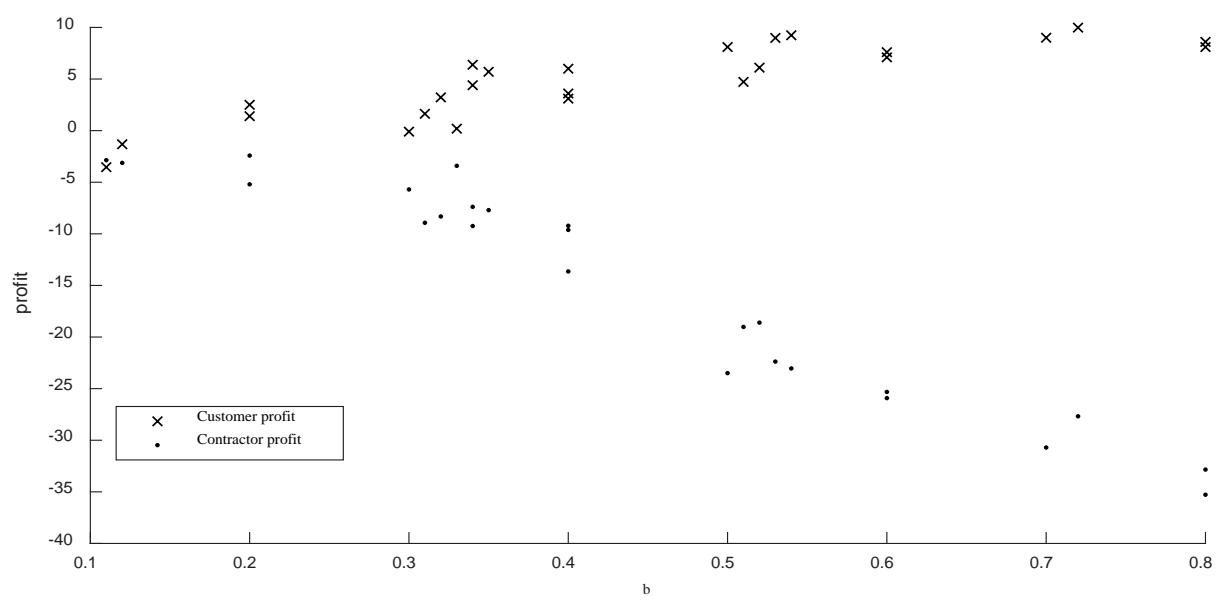

Fig.2 Cost-based incentive contracts

Further explore the incentive coefficient under different incentive contracts and the relationship between the two parties. We also calculate the benefits of both parties according to the contract. The scatter plot of excitation coefficient and benefit in progress-based and cost-based contract shown in Fig.1 and Fig.2.

According to the analysis figure, in the incentive contract based on progress and cost, with the increase of the incentive coefficient, the owner's income presents an upward trend. In a cost-based incentive contract, the incentive coefficient is negatively correlated with the contractor's benefits. In the contract based on progress, with the increase of incentive coefficient, the contractor's benefit first decreases and then increases. It can be seen that different incentive contracts have no obvious difference in owners' income, but different benefits to contractors. In terms of benefits, it is better for the contractor to enter into a contract based on progress.

\section{Conclusion}

This paper studies the incentive effect of different contracts. The results show that the incentive coefficient and effort degree based on the progress contract are lower than that based on the cost 
incentive contract. There was no significant difference in incentive coefficient between the two contracts, but there was significant difference in effort. In terms of benefits, there is no significant difference between the two types of contracts to the owner, while for the contractor, it is better to sign the incentive contract based on progress than the incentive contract based on cost.

\section{References}

[1] Jinhui Zhou. Application of earned value management in software project's cost and schedule monitoring [J].Systems engineering and electronics, 2006, 28(4).

[2] Ziman Chen. Research on evaluation of quality earned value method based on risk factors [J].Highway transportation technology, 2017, 145(1).

[3] Yanming Wei. Earned value method in the total cost variance analysis for land development and consolidation project [J].China land science, 2011, 25(5).

[4] Rodney Howes. Improving the performance of earned value analysis as a construction project management tool [J].Engineering Construction and Management, 2000.7(4).

[5] Fleming Keppelman. Earned value management: Mitigating the risks associated with construction projects [J].Cost Engineering, 2002,9(4).

[6] Anbari FT. Earned value Management: Method and extensions [J].Project Management Journal, 2003, 34(4).

[7] Chunsheng Dai. Earned value management of IT project based on vague sets theory.[J]Operations research and management science,2017.9,26(9).

[8] Anbang Qi. Errors and solutions in the projects earned value analysis method [J].The journal of quantitative \& technical economics, 2004, (5).

[9] Rui Lu. Research on project cost performance evaluation method using earned value of risk [J].Journal of Dalian university of technology, 2011, 51(2).

[10] Qiang Mou. Improving cost estimate at competition of the Duration-fixed mega construction project.[J]Chinese Journal of Management Science,2018.4,26(4).

[11] Guangping Liu, Liwen Chen. Research on improved method for project performance evaluation based on earned valued management [J].Forecasting, 2013, 32(4).

[12] Guangping Liu, Liwen Chen. Project contact incentive mechanism and scheme designing based on earned value management method [J].System Engeering, 2014, 32(5). 